\title{
Plasma 'ketone' level in the diagnosis and treatment of diabetic acidosis
}

\author{
M. S. KNAPP \\ M.D., M.R.C.P. \\ Lecturer in Medicine, University of Bristol
}

\author{
MARGARET E. HoRN \\ M.B., M.R.C.P. \\ Medical Registrar, Bristol Royal Hospital
}

\section{Summary}

A simple method of estimating the plasma 'ketone' level with 'Acetest' tablets has been used in the diagnosis and treatment of diabetic acidosis. The method is valuable when used in association with full biochemical facilities, but it is especially useful in situations where these cannot be easily obtained.

\section{Introduction}

In a patient suspected of having diabetic ketoacidosis it is useful to be able to rapidly confirm the diagnosis. In this situation we have used a simple side-room method for the detection of plasma ketones and now report our experience with it.

Rothera (1908) described a method of identifying ketone bodies in urine which depends on the reaction between sodium nitroprusside and acetoacetic acid in the presence of free ammonium ions. Wishart (1920) adapted this method for use with plasma. We have used 'Acetest' (Ames \& Co. Ltd) tablets, which are based on this reaction, as a qualitative and quantitative measurement of plasma 'ketones'. 'Acetest' tablets react with both aceto-acetate and acetone but they are more sensitive to the former, therefore the reaction is mainly a measure of the aceto-acetate concentration. The concentration of aceto-acetate correlates with the severity of diabetic ketoacidosis (Nabarro, 1962).

\section{Methods}

Venous blood was collected into a heparinized container. After separation the plasma was drawn off with a syringe or pipette. A drop of plasma was placed on a crushed 'Acetest' tablet and inspected after half a minute. If a postive result was obtained a series of dilutions was made, i.e. $1: 2,1: 4,1: 8,1: 16$, etc., and the test repeated. The highest dilution that produced a definite purple colour, i.e. comparable to that indicating one plus ketonuria on the chart provided by Ames was recorded.
All patients in possible diabetic acidosis admitted to one of the medical firms at the Bristol Royal Infirmary over a 3-year period had an estimation of the plasma 'ketone' level performed by the clinical staff in the ward side-room. In those patients treated for a moderate or severe diabetic keto-acidosis the estimation was repeated, usually every four hours. The second and subsequent doses of insulin were based to a considerable extent on the plasma 'ketone' titre. If the titre had not fallen or had risen, an increased dose of insulin was given. A fall in titre indicated a satisfactory response and either a similar dose or a smaller one was used, depending on previous blood sugar results.

In all patients blood was sent to the laboratory for measurement of blood glucose, blood urea and electrolytes (including bicarbonate). Urine was examined for reducing sugars with 'Clinitest' tablets and for ketones with 'Acetest' tablets and Gerhardt's reaction (port-wine colour on addition of ferric chloride).

\section{Results}

Brief clinical details of eight patients admitted in diabetic keto-acidosis are listed in Table 1. The patients' ages ranged from 14 to 72 years. Two were previously undiagnosed, the rest developed ketosis as the result of an infection or an inappropriate reduction in insulin dose. All but one of the diabetics previously treated had been taking insulin. The plasma from all these patients gave a positive reaction with 'Acetest' with dilutions of $1: 8$ or higher. Only one patient was seen who did not have a positive test at this dilution but had sufficient acidosis to depress the serum bicarbonate: she was shown to have a lactic acidosis and is described in more detail (Case 9).

The patients were not catheterized and in some the first urine was obtained after the start of treatment. Only two patients did not show heavy glycosuria and ketonuria as evaluated by Gerhardt's reaction. The first of these was a patient (Case 3) with renal failure who had only 
TABLE 1

Patients admitted with diabetic acidosis

\begin{tabular}{|c|c|c|c|c|c|c|c|c|c|}
\hline Patient & Age & Sex & $\begin{array}{l}\text { Comments: precipitating cause } \\
\text { (if known) }\end{array}$ & $\begin{array}{l}\text { Duration of } \\
\text { prodromal } \\
\text { symptoms }\end{array}$ & $\begin{array}{l}\text { Blood } \\
\text { sugar } \\
(\mathrm{mg} / 100 \mathrm{ml})\end{array}$ & $\begin{array}{l}\text { Plasma bi- } \\
\text { carbonate } \\
(\mathrm{mEq} / 1)\end{array}$ & $\begin{array}{c}\text { Plasma } \\
\text { ketones } \\
\text { (titre) }\end{array}$ & $\begin{array}{c}\text { Urine } \\
\text { sugar } \\
(\%)\end{array}$ & $\begin{array}{c}\text { Urine } \\
\text { ketones } \\
\text { Gerhardt's }\end{array}$ \\
\hline 1 & 76 & F & Pneumonia. Semicomatose & 7 days & 590 & $7 \cdot 5$ & $1: 8$ & $>2$ & $+\mathrm{ve}$ \\
\hline 2 & 27 & $\mathbf{M}$ & $\begin{array}{l}\text { Polyuria. Polydipsia. } \\
\text { Semi-comatose }\end{array}$ & 28 days & 900 & $12 \cdot 5$ & $1: 16$ & $>4$ & $+\mathrm{ve}$ \\
\hline 3 & 58 & $\mathbf{F}$ & $\begin{array}{l}\text { Diabetic nephropathy. Blood } \\
\text { urea }=200 \mathrm{mg} / 100 \mathrm{ml} \text { before ketosis }\end{array}$ & 2 days & 1000 & $12 \cdot 5$ & $1: 16$ & 2 & - ve \\
\hline 4 & 14 & $\mathbf{M}$ & Polyuria. Polydipsia. Drowsy & 28 days & 580 & 14 & $1: 16$ & 16 & + ve \\
\hline 5 & 16 & $\mathbf{M}$ & $\begin{array}{l}\text { 'Stopped insulin' } 48 \mathrm{hr} \text {. } \\
\text { Semi-conscious }\end{array}$ & $24 \mathrm{hr}$ & 980 & $6 \cdot 6$ & $1: 32$ & $>2$ & $+\mathrm{ve}$ \\
\hline 6 & 22 & $\mathbf{F}$ & $\begin{array}{l}\text { Polydipsia. Polyuria. } \\
\text { Dehydrated. Alert }\end{array}$ & 7 days & 470 & $12 \cdot 5$ & $1: 8$ & $>2$ & + ve \\
\hline 7 & 19 & $\mathbf{F}$ & Acute urinary tract infection & 5 days & 600 & $<5$ & $1: 32$ & $>2$ & + ve \\
\hline 8 & 64 & $\mathbf{F}$ & 'Stopped insulin' & 2 days & 1900 & $<10$ & $1: 8$ & $>2$ & $+\mathrm{ve}$ \\
\hline 9 & 40 & $\mathbf{F}$ & Staphylococcal septicaemia & $24 \mathrm{hr}$ & 160 & $<10$ & Nil & $\mathbf{0}$ & - ve \\
\hline
\end{tabular}

Patients 1-8 had diabetic keto-acidosis. Patient 9 had lactic acidosis.

$2 \%$ glycosuria and very slight ketonuria, positive to 'Acetest' but not to Gerhardt's reaction. The second was the diabetic with lactic acidosis who had no ketonuria.

During this period several other diabetic patients were found to have a positive Gerhardt's reaction in the urine but a normal serum bicarbonate level. Plasma ketones were absent or only detected in undiluted plasma in these patients. All of them responded rapidly to a moderate increase in insulin dosage.

All patients with keto-acidosis were treated with insulin. The treatment of three patients is described (Cases 1-3 and Figs. 1-3) to illustrate the way in which it is based on plasma ketone titre according to the principles already outlined. In all cases the change in plasma 'ketone' level reflected changes in the blood glucose and plasma bicarbonate level.

\section{Case reports}

\section{Case 1}

A 76-year-old diabetic woman was admitted semi-comatose. The plasma ketone titre was $1: 8$ and the blood sugar $590 \mathrm{mg} / 100 \mathrm{ml}$. Seventy-five units of soluble insulin were given. Four hours later the plasma ketone titre had fallen to $1: 4$ so a smaller dose of insulin was given. Eight hours later the plasma ketone titre had fallen to $1: 2$. The 4 -hr blood sugar result was now available and the level had fallen very little from the initial value. The dose of inuslin was, therefore, slightly increased. At $14 \mathrm{hr}$ the plasma ketone titre was still $1: 2$ so the dose of insulin was doubled. This promptly caused a fall in the plasma ketone titre and with a further small dose of insulin they became undectable at $23 \mathrm{hr}$.

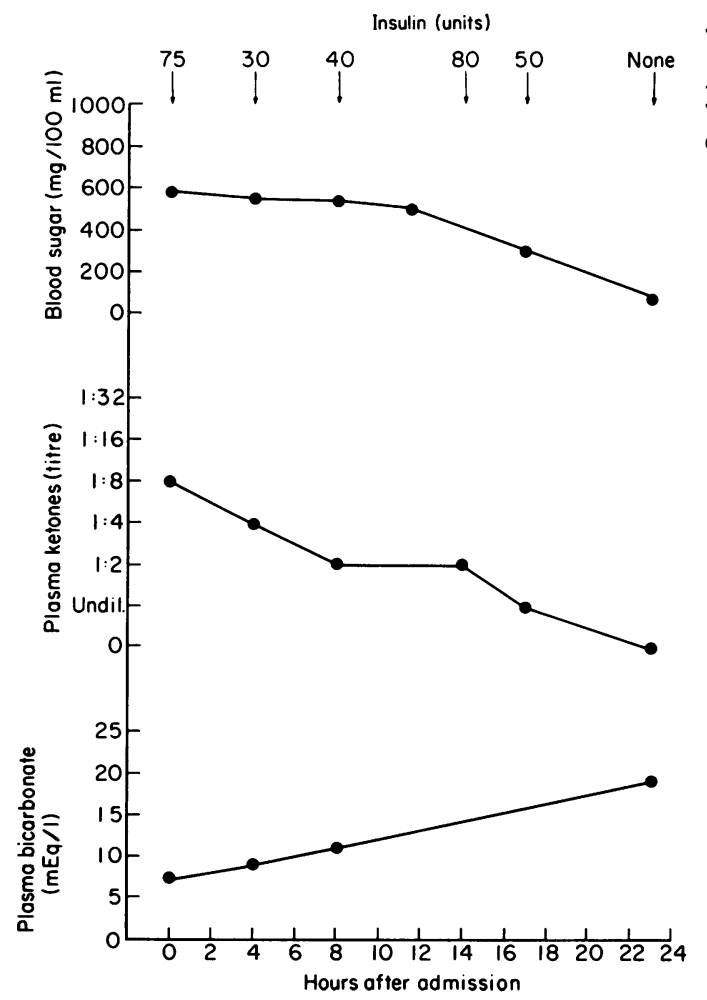

Fig. 1. Plasma ketone titre, blood sugar and plasma bicarbonate levels in Case 1 . 


\section{Case 2}

A 27-year-old male was admitted semicomatose, a history of polyuria and polydipsia was obtained. The plasma ketone titre was $1: 16$ and the blood sugar $900 \mathrm{mg} / 100 \mathrm{ml}$. After an initial dose of 75 units of soluble insulin his plasma ketone titre had fallen to $1: 8$ at $6 \mathrm{hr}$. Forty units of soluble insulin were then given and resulted in a further fall in titre to $1: 2$ at $12 \mathrm{hr}$. He received 20 units of soluble insulin and plasma ketones became undetectable at $18 \mathrm{hr}$.

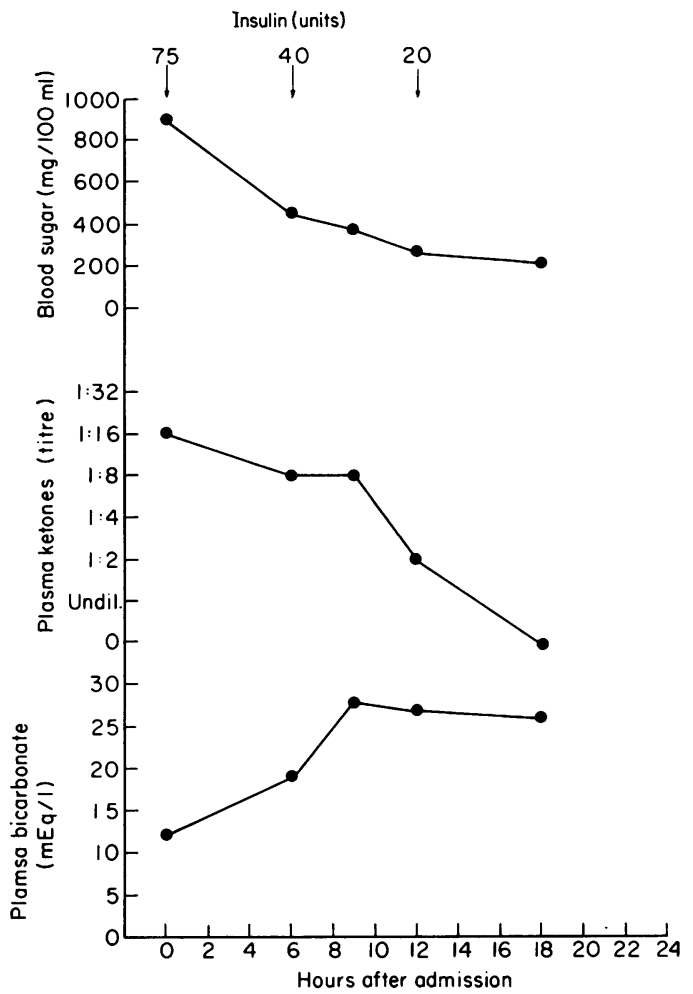

Fig. 2. Plasma ketone titre, blood sugar and plasma bicarbonate levels in Case 2 .

\section{Case 3}

This 58-year-old woman was known to have severe diabetic nephropathy with blood urea levels consistently over $200 \mathrm{mg} / 100 \mathrm{ml}$. Since admission to hospital only small amounts of sugar and no ketones had been present in her urine. For 2 days she was drowsy and the urine sugar concentration increased to $2 \%$ but not above. The urine contained only a trace of ketones to 'Acetest' tablets. The cause of her deterioration was diagnosed when the plasma 'ketone' estimation was made, for a positive reaction occurred at 1 : 16 dilution. The blood sugar was $1000 \mathrm{mg} /$
$100 \mathrm{ml}$ and the bicarbonate $12.5 \mathrm{mEq} / 1$. In view of the renal failure she received a small initial dose of 50 units of soluble insulin. After $3 \mathrm{hr}$ the plasma ketone titre had fallen to $1: 4$ and as the initial blood sugar was very high a further 50 units of insulin were given. At $8 \mathrm{hr}$ ketones were detected only in the undiluted plasma. After a small dose of insulin they became undetectable $4 \mathrm{hr}$ later.

Case 9

A woman aged 40 years with longstanding diabetes was admitted to hospital with a staphylococcal septicaemia. She received antibiotics. Her diabetes was treated with a $50 \mathrm{~g}$ carbohydrate meal every $6 \mathrm{hr}$, and a dose of insulin before it depending on the degree of glycosuria.

One week after admission she became confused and started to hyperventilate. On examination she looked like a patient in diabetic precoma but the urine and blood contained no ketones. Investigations showed: blood glucose 160 , urea $56 \mathrm{mg} / 100 \mathrm{ml}$, sodium 127 , potassium 6.8 bicarbonate $10 \mathrm{mEq} / 1, \mathrm{pH} \mathrm{7.25}, \mathrm{PCO}_{2} 34 \mathrm{~mm}$. In view of the marked acidosis without ketosis the

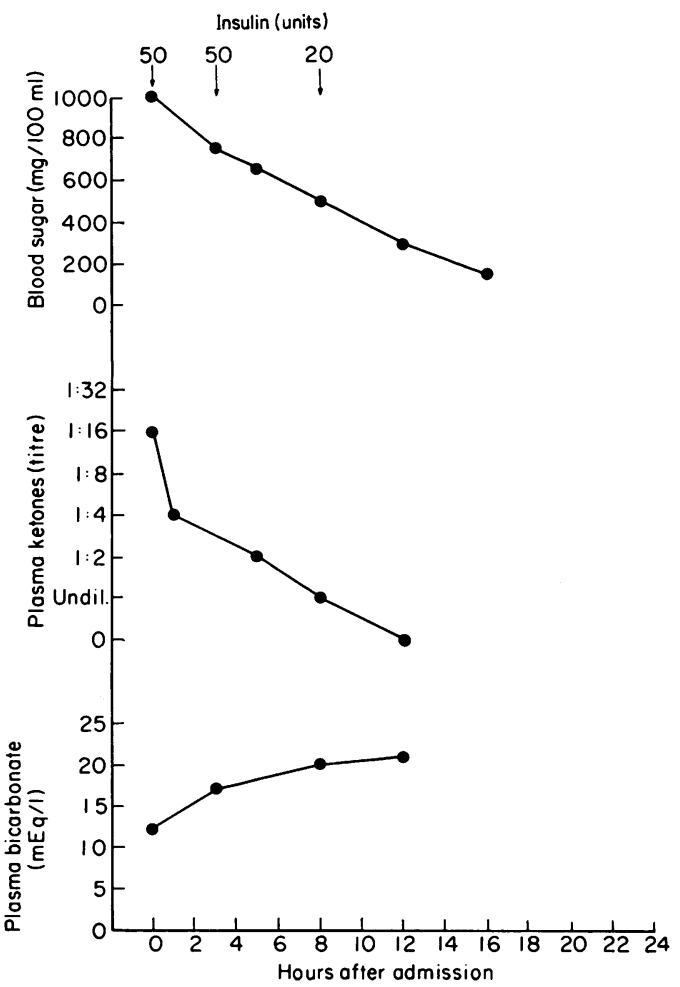

Fig. 3. Plasma ketone titre, blood sugar and plasma bicarbonate levels in Case 3. 
serum lactic acid was measured and found to be markedly elevated at $15.5 \mathrm{mEq} / 1$. Correction of her acidosis with sodium bicarbonate resulted in improvement in her clinical and biochemical state. Later the lactic acidosis recurred and again the diagnosis was made when a severe acidosis without ketonaemia was demonstrated.

\section{Discussion}

We found this simple test rapidly confirmed the clinical diagnosis of diabetic keto-acidosis, being especially useful when the patient was unable to pass urine. It also enabled us to diagnose significant ketosis in the patient with renal failure (Case 3) and to suspect lactic acidosis in Case 9.

We did not find ketonaemia, even in undiluted plasma, except in diabetics. At concentrations which gave a positive reaction at $1: 4$ dilution metabolic acidosis due to diabetes was present. Lee \& Duncan (1956) also found strong positive reactions only in diabetic acidosis.

We found the test of considerable help in the management of our patients. It is well known that the response to insulin is variable and it is usual to give an empirical first dose, perhaps varying the amount with the height of the initial blood glucose. Subsequent doses are then based on the change which occurs in blood glucose or bicarbonate concentration. The plasma 'ketone' level gave an indication of the effect of the previous dose of insulin. This method of deciding the next dose was as satisfactory as the blood sugar or the bicarbonate level and the result much more quickly available.

It is inevitable that many hospital laboratories, with a heavy load of routine and emergency work, will not always be able to provide results of biochemical estimations within $\frac{1}{2} \mathrm{hr}$ of a sample being taken. After this time, as the patient's metabolic state is changing, the result begins to lose its value. This side-room test for plasma ketones takes only a few minutes and provides information on which immediate decisions regarding treatment can be made. If in addition the electrocardiogram is used to check for serious errors in potassium administration, the haematocrit to assist in assessing hydration and 'Dextrostix' (Ames \& Co. Ltd) to detect a fall in blood sugar to below $200 \mathrm{mg} / 100 \mathrm{ml}$ the management of a patient with severe diabetic keto-acidosis can be undertaken with minimal laboratory services. When laboratory services are available the results of blood glucose, electrolytes and $\mathrm{pH}$ should be used to confirm these results.
In unusual cases of diabetic coma due to lactic acidosis (Daughaday, Lipicky \& Rasinski, 1962) the estimation of the plasma 'ketone' level is of considerable value in diagnosis although it is of no value in following treatment. If a clinical or biochemical acidosis is found in a diabetic the absence of plasma ketones suggests the possibility of lactic acidosis or some other metabolic acidosis, e.g. renal failure. It is important to diagnose lactic acidosis as sodium bicarbonate must be used to treat this condition rather than sodium lactate which may be used to treat diabetic keto-acidosis.

It is also important to distinguish those cases of diabetic coma due to extreme hyperosmolality as the principles of treatment are different (Halmos, Nelson \& Lowery, 1966). A patient with clinically severe dehydration and coma, apparently due to diabetes, should be immediately suspected of falling into this group if the serum ketone test is not positive at the $1: 4$ dilution. In these patients the treatment cannot be monitored with serum ketone levels.

Nabarro (1962) suggested that the plasma ketone level might be of considerable value in the management of diabetes. Our experience demonstrates that it is an important aid in diag nosing and treating diabetıc keto-acidosis and should be more widely used.

Since the submission of this paper Watkins FitzGerald (1968) have shown that 'Ketostix' strips are easier to use than 'Acetest' tablets for these estimations.

\section{Acknowledgments}

We would like to thank Dr J. E. Cates, under whose care most of these patients were admitted, for his assistance in the preparation of this paper. One of us was introduced to this method by the residents at Duke University, North Carolina, U.S.A., to whom we are very grateful.

\section{References}

Daughaday, W.H., LiPICKY, R.J. \& RAsinski, D.C. (1962) Lactic acidosis as a cause of nonketotic acidosis in diabetic patients. New Engl. J. Med. 267, 1010.

Halmos, P.B., Nelson, J.K. \& Lowery, R.C. (1966) Hyperosmolar nonketoacidotic coma in diabetes. Lancet, i, 675.

LEE, C.T. \& DunCAN, G.C. (1956) Diabetic coma: the value of a simple test for acetone in the plasma - an aid to diagnosis and treatment. Metabolism, 5, 144.

NABARRO, J.D.N. (1962) Treatment of severe diabetic ketosis. Disorders of Carbohydrate Metabolism (Ed. by D. A. Pyke). Pitman, London.

ROTHERA, A.C.H. (1908) Note on sodium nitro-prusside reaction for acetone. J. Physiol. (Lond.), 37, 491.

Watkins, P.J. \& FitzGerald, M.G. (1968) An evaluation of 'Ketostix' strips. Diabetes, 17, 398.

WisharT, M. (1920) Quoted by F. M. Allen in: Nelson's Medicine, 4, 77. 